\title{
Extraction and antimicrobial activity of rhamnolipid biosurfactant produced by Pseudomonas aeruginosa UKMP14T
}

\author{
Ayesha Firdose $^{1}$, Marwan Jawad Msarah ${ }^{1,2}$, Nur Hazlin Hazrin Chong ${ }^{1}$ and Wan Syaidatul Aqma ${ }^{1 *}$ \\ ${ }^{1}$ Department of Biological Sciences and Biotechnology, Faculty of Science and Technology, \\ Universiti Kebangsaan Malaysia, 43600 Bangi, Selangor, Malaysia. \\ ${ }^{2}$ Department of Radiology Technologies, Al-Hadi University, 10022, Baghdad, Iraq. \\ Email: syaidatul@ukm.edu.my
}

Received 6 March 2020; Received in revised form 30 May 2020; Accepted 30 October 2020

\begin{abstract}
Aims: Rhamnolipids are seeking utmost attention as a new class of biosurfactants having promising potential in diverse fields as they offer a wide range of advantages over chemically synthesised surfactants. However, the high extraction costs make large scale production face difficulty. In present study, hydrocarbon degrading bacteria Pseudomonas aeruginosa UKMP14T was exploited for its biosurfactant producing ability including a comparative study between different extraction procedures for its recovery. In addition to this, the recovered biosurfactant was explored for its potential application as an antimicrobial agent.

Methodology and results: The production of rhamnolipid biosurfactant was confirmed through various detection methods which are drop-collapse test, oil spreading assay, emulsification index, cetyltrimethylammonium bromide (CTAB) assay and hemolytic assay. The test strain $P$. aeruginosa UKMP14T showed positive results for all the detection assays. Following this, shake flask cultivation was carried out for several time intervals (1, 3, 5, 7 and 9 days) to discover the optimum time for rhamnolipid biosurfactant production. The results were evaluated by quantifying the rhamnolipid yield using Anthrone method and maximum yield was obtained on day 7 . Then, three commonly employed rhamnolipid biosurfactant extraction methods (acid precipitation, solvent extraction and zinc sulphate precipitation) were incorporated for the extraction of rhamnolipid biosurfactant. Among these methods, organic solvent extraction (using methanol, chloroform and acetone in 1:1:1 ratio) gave the highest yield $(7.37 \pm 0.81 \mathrm{~g} / \mathrm{L})$ of biosurfactant, followed by zinc sulphate precipitation $(5.83 \pm 0.02 \mathrm{~g} / \mathrm{L})$, whereas acid precipitation gave the lowest yield $(2.8 \pm 0.12 \mathrm{~g} / \mathrm{L})$ and required longer time (30 days). Finally, the antimicrobial activity of several concentrations of rhamnolipid was tested using modified microdilution method and highest antibacterial activity (in the form of percent reduction in growth) of $95.05 \%$ and $91.89 \%$ was recorded for Escherichia coli ATCC 10536 and Staphylococcus aureus ATCC 11632, respectively, at $100 \mu \mathrm{g} / \mathrm{mL}$ concentration of rhamnolipid biosurfactant.

Conclusion, significance and impact of study: The ability of $P$. aeruginosa UKMP14T in producing rhamnolipid biosurfactant was confirmed. Despite the higher yield obtained by organic solvent extraction method, the recovery technique (involving the separation of solvent system) caused some loss in product. In addition, the transfer and storage of rhamnolipid was challenging using solvent extraction in comparison to acid precipitation and zinc sulphate precipitation. On the other hand, recovery using acid precipitation suffered from lowest yield of rhamnolipid. Therefore, zinc sulphate precipitation is prioritised over the other two methods. Furthermore, the antimicrobial potential of rhamnolipid biosurfactant was tested successfully for as low as $10 \mu \mathrm{g} / \mathrm{mL}$ concentration against E. coli ATCC 10536 and $S$. aureus ATCC 11632. Therefore, the recovery cost of a high value product like rhamnolipid can be reduced by incorporating the results of this study in the downstream processing and promote rhamnolipid biosurfactant as a potential antimicrobial agent.
\end{abstract}

Keywords: Rhamnolipid, biosurfactant, antimicrobial, Pseudomonas aeruginosa, extraction

\section{INTRODUCTION}

Biosurfactants are the surfactants of low molecular weight produced by microorganisms. They are heterogeneous group of surface active molecules which are amphiphilic in nature produced by microbes on cell surface or secreted extracellularly. They consist of a hydrophilic (polar or nonpolar) and a hydrophobic moiety (lipid or fatty acid) in their structure. Due to this unique property, they possess the ability to solubilise insoluble compounds like 
hydrocarbons (Shah et al., 2016). The ability of biosurfactants to reduce the surface and interfacial tension afford them exceptional detergency, emulsification, foaming, and dispersing characteristics (Shekhar et al., 2015). They offer several advantages over synthetic surfactants as they are diverse, biodegradable and have minimal toxicity. In addition, biosurfactants are also effective at extreme levels of temperature, $\mathrm{pH}$ and wide range of salt concentrations (Muthusamy et al., 2008). Microbial biosurfactants have made their mark with respect to their applicability in environmental protection, which majorly includes the enhancement of oil recovery, oil spills control, biodegradation and detoxification of industrial effluents and soils polluted with oil. Apart from this, biosurfactants are also well known for their application in pharmaceutical, medical, food, cosmetic and pesticides industries (Nitschke and Costa, 2007; Banat et al., 2010; Soberon-Chavez and Maier, 2011; Fracchia et al., 2012; Gudina et al., 2013).

Rhamnolipids are one of the prominent categories of biosurfactants produced by a variety of microorganisms like Pseudomonas aeruginosa, $P$. fluorescens and Serratia rubidaea (El-Amine et al., 2012; Nalini and Parthasarathi, 2014). Among these, $P$. aeruginosa is said to be the best strain for rhamnolipid production, and is studied extensively (Rikalovic et al., 2012). Applications of rhamnolipids are noteworthy in various industries such as agriculture, microbial enhanced oil recovery and bioremediation of oil-contaminated sites (Banat et al., 2000). Although considerable amount of work has been dedicated in improvisation of fermentation technology, the applicability of biosurfactants still remains limited. The main reason for this is the high cost incurred in product recovery due to the infeasibility of methods at a large scale (Shah et al., 2016).

The potential applications of biosurfactants from the genus Pseudomonas as a successful antimicrobial agent have been demonstrated by several researchers. For example, the biosurfactant produced by $P$. aeruginosa PB3A showed wide range of antimicrobial activity against Staphylococcus aureus ATCC 29736, S. epidermidis ATCC 12228, Escherichia coli ATCC 8739 and $P$. aeruginosa ATCC 27853 strains used in the study conducted by Vijayakumar and Saravanan in 2015. In addition, Rodrigues et al. (2004) demonstrated that rhamnolipids have the antimicrobial activity against pathogenic bacteria isolated from explanted voice prostheses to silicone rubber. Furthermore, rhamnolipid applications as antimicrobial agent in preventing food spoilage and for sanitization in food manufacturing industries have been pointed out by several researchers (Irie et al., 2005; Vatsa et al., 2010). The prevention of biofilm formation owing to the anti-adhesive nature of rhamnolipid has also been highlighted against the foodborne pathogenic bacteria Listeria monocytogenes and Bacillus subtilis (Magalhaes and Nitschke, 2013).

Despite the numerous applications afforded by rhamnolipid biosurfactants, they still lack a proper recognition in market because of the high production costs involved coupled with minimal yield obtained Therefore, a comparative analysis between the extraction methods can contribute to knowledge that can be incorporated as a better extraction method that can be feasible even at industrial level/ for large scale production. Additionally, the potential of rhamnolipids as antimicrobials has already been described by several researchers. However, this paper provides a preliminary analysis of a rhamnolipid biosurfactant as a potential antibacterial agent being extracted from a native bacterial species ( $P$. aeruginosa UKMP14T) sampled from Malaysia.

\section{MATERIALS AND METHODS}

\section{Inoculum and media preparation}

The bacterial strain $P$. aeruginosa UKMP14T previously isolated from oil contaminated soil was obtained from Culture Collections Laboratory, Department of Biological Sciences and Biotechnology, Universiti Kebangsaan Malaysia. Firstly, the culture was subjected for revival in order to prepare the inoculum. The mother culture was revived following the standard microbiological protocols. Briefly, a loop full of culture from the previous stock was inoculated into a $100 \mathrm{~mL}$ shake flask containing $50 \mathrm{~mL}$ nutrient broth and was kept in incubator shaker at a speed of $180 \mathrm{rpm}$ for $24 \mathrm{~h}$. After $24 \mathrm{~h}$, a loop full of inoculum was taken from the fresh broth and streaked over several nutrient agar plates using quadrant streaking technique. The plates were further incubated and kept at $4{ }^{\circ} \mathrm{C}$ for later use. Modified mineral salt medium (MSM) was used throughout the study for production of rhamnolipid biosurfactant. This media contained $0.1 \%$ $(\mathrm{v} / \mathrm{v})$ vitamins and trace elements and for carbon source it was supplemented with $1 \%(\mathrm{v} / \mathrm{v})$ glycerol (Hamzah et al., 2010). The $\mathrm{pH}$ of the medium was adjusted to 7.0 with 1 $\mathrm{M}$ sodium hydroxide $(\mathrm{NaOH})$ or $1 \mathrm{M}$ hydrochloric acid $(\mathrm{HCl})$. The medium was autoclaved at $121^{\circ} \mathrm{C}, 15 \mathrm{psi}$ for 15 min before use.

\section{Screening for biosurfactant production}

A standard inoculum of $P$. aeruginosa UKMP14T was prepared in nutrient agar according to the method of Hamzah et al. (2010). The density of cells was standardised by adjusting the OD reading to 0.5 at 590 $\mathrm{nm}$ which approximates to $10^{5} \mathrm{CFU} / \mathrm{mL}$. About $10 \%(\mathrm{v} / \mathrm{v})$ of this inoculum was inoculated into $50 \mathrm{~mL}$ of MSM contained in a $250 \mathrm{~mL}$ conical flask and incubated as previously described. After a period of $24 \mathrm{~h}$, the culture medium was centrifuged at $8022 \mathrm{~g}$ (RC5C Sorvall Centrifuge Instrument, USA) at $4{ }^{\circ} \mathrm{C}$ for $30 \mathrm{~min}$. The supernatant was collected and used for preliminary screening of biosurfactant presence.

\section{Qualitative screening for biosurfactant detection drop-collapse test}

The drop-collapse test was carried out as described by 
Bodour and Miller-Maier (1998). Briefly, $2 \mu \mathrm{L}$ of Tapis crude oil (supplied by Petronas Research Scientific Berhad, Malaysia) was applied to the wells of a 96 well plate $\left(12.7 \times 8.6 \mathrm{~cm}^{2}\right)$ (Corning Incorporated, USA) and left to equilibrate for a period of $24 \mathrm{~h}$ (Hamzah et al., 2013). Then, a drop of supernatant (after removing cells by centrifuging at $8022 \mathrm{~g}$ for 30 mins) was placed on the oil-coated wells. The drop was observed after 1 min using a magnifying glass. Sodium dodecyl sulphate (SDS) and distilled water were used as positive and negative controls respectively. The results were recorded as negative if the drop remained beaded even after $1 \mathrm{~min}$ and, scored positive if the drop collapsed.

\section{Oil spreading assay}

The oil spreading technique was performed based on the method suggested by Youssef et al. (2004). In this method, $20 \mathrm{~mL}$ of distilled water was added to a Petri dish $(90 \mathrm{~mm} \times 15 \mathrm{~mm})$ followed by addition of $20 \mu \mathrm{L}$ of Tapis crude oil to the surface of water. Then, $10 \mu \mathrm{L}$ of supernatant was dropped onto the Tapis crude oil surface. The Petri dish was observed for appearance of oil free clear zone on the surface of water which is an indication of the surfactant activity. SDS and distilled water were used as positive and negative controls, respectively.

\section{Emulsification index (\%El 24$)$}

The $\% \mathrm{El}_{24}$ was determined using the method based on Cooper and Goldenberg (1987). Equal volume of Tapis crude oil was added to the supernatant $(1: 1)$ and was mixed using a glass test tube $(125 \mathrm{~mm} \times 15 \mathrm{~mm})$. Then, the mixture was vortexed for 2 min and left to stand for 24 h. The $\% \mathrm{El}_{24}$ was calculated using the formula below. A higher value indicates a higher emulsification activity of the tested surfactant. SDS was used as the positive control, whereas distilled water was used as the negative control for this assay.

$$
\% \mathrm{El}_{24}=\frac{\text { Height of the emulsion layer }(\mathrm{mm})}{\text { Total height }(\mathrm{mm})} \times 100
$$

\section{Hemolytic assay}

Fresh blood agar plates were prepared and pure culture of $P$. aeruginosa UKMP14T was streaked on the agar plate and incubated at $37{ }^{\circ} \mathrm{C}$ for $24-48 \mathrm{~h}$. The presence of clear zone around the colonies indicated the presence of biosurfactant producing organisms. Results were recorded based on the type of clear zone observed i.e., when the colony was surrounded by greenish zone $-\alpha$ hemolysis, clear white zone - $\beta$-hemolysis and no change in the medium surrounding the colony $-y$ hemolysis (Carrillo et al., 1996).

\section{Cetyltrimethylammonium bromide (CTAB) assay}

This method was performed as described by Vijayakumar and Saravanan (2015). Briefly, mineral salt agar medium supplemented with glucose as carbon source $(2 \%)$ and cetyltrimethylammonium bromide (CTAB: $0.5 \mathrm{mg} / \mathrm{mL}$ ) and methylene blue (MB: $0.2 \mathrm{mg} / \mathrm{mL}$ ) was autoclaved at 121 ${ }^{\circ} \mathrm{C}$ for $15 \mathrm{~min}$. After autoclaving, the media was poured into Petri dishes and allowed to solidify. Then, the wells were punctured into the agar using borer $(4 \mathrm{~mm})$. Following this, $30 \mu \mathrm{L}$ of culture broth supernatant was added into the wells using micropipette. Similarly, SDS and sterile distilled water were added to the methylene blue agar plate wells as positive and negative controls, respectively, and the plates were incubated at $37^{\circ} \mathrm{C}$ for 48-72 $\mathrm{h}$ in an incubator (Yihder Technology, China). A dark blue halo zone around the well was taken as a positive result for anionic biosurfactant production.

\section{Quantitative screening for biosurfactant detection}

Rhamnolipid was quantified using Anthrone method as described below (Bailey, 1958). The quantification of rhamnolipid was carried out in an indirect way, by measuring the amount of rhamnose. Rhamnose is a byproduct obtained on acid hydrolysis of rhamnolipids and this was used as a reference in this assay. Therefore, the extracellularly produced rhamnolipid was quantified by measuring the concentration of rhamnose. At first, Anthrone reagent was prepared by dissolving about 20 $\mathrm{mg}$ of Anthrone (Sigma Aldrich, USA) in 70\% sulphuric acid $\left(\mathrm{H}_{2} \mathrm{SO}_{4}\right)$ and it was allowed to stand for $2 \mathrm{~h}$ at $4{ }^{\circ} \mathrm{C}$. Following this, $0.2-1 \mathrm{~mL}$ rhamnose solutions were pipetted into clean and dry test tubes $(20 \mathrm{~cm} \times 2 \mathrm{~cm})$. In addition to this, $0.5 \mathrm{~mL}$ of culture supernatant was pipetted into separate test tubes labelled as 'Test'. The volume in each tube was made up to $1 \mathrm{~mL}$ with distilled water. The tubes were kept in ice and agitated whilst the Anthrone reagent $(4 \mathrm{~mL})$ was being added slowly to each tube. The tubes were stoppered, and the contents were vortexed for a minute. Then, the tubes were kept in a boiling water bath at $90{ }^{\circ} \mathrm{C}$ for $10 \mathrm{~min}$ and then transferred to ice box for cooling. Following this, the tubes were left in dark for $30 \mathrm{~min}$. The greenish-blue color developed was measured against blank at an absorbance of $630 \mathrm{~nm}$ in a spectrophotometer (Biochrom Libra, UK). A standard curve of L-rhamnose was plotted and the rhamnolipid biosurfactant concentration was calculated by extrapolating the OD values obtained.

\section{Shake flask cultivation}

To optimise the best time interval required for the production of biosurfactant, a standardised inoculum of the isolate was prepared as described earlier. Then, $10 \%$ $(\mathrm{v} / \mathrm{v})$ of this standardized inoculum was inoculated into five separate flasks (500 mL capacity) containing $200 \mathrm{~mL}$ of MSM. Further, $1 \%(\mathrm{v} / \mathrm{v})$ glycerol was added to all flasks and incubated at $37^{\circ} \mathrm{C}$ on an orbital shaker with agitation speed $150 \mathrm{rpm}$. Later, the contents from respectively 
labelled flasks were withdrawn on day 1, 3, 5, 7 and 9 for quantifying the rhamnolipid using Anthrone assay as discussed in the previous section.

\section{Biosurfactant extraction}

After incubating for optimum number of days required for biosurfactant production, the culture medium was centrifuged at $8022 \mathrm{~g}$ (RC5C Sorvall Centrifuge Instrument, USA) at $4{ }^{\circ} \mathrm{C}$ for $30 \mathrm{~min}$. The supernatant was collected and used for extraction of the rhamnolipid biosurfactant using three separate approaches as mentioned below.

\section{Acid precipitation}

The supernatant containing biosurfactant was acidified to $\mathrm{pH} 2.0$ using $1 \mathrm{M} \mathrm{HCl}$. This was left up to 4 weeks at $4{ }^{\circ} \mathrm{C}$ until the biosurfactant precipitated completely. At $1^{\text {st }}, 2^{\text {nd }}$ $3^{\text {rd }}$ and $4^{\text {th }}$ week interval, the solution containing the precipitate was centrifuged at $8022 \mathrm{~g}$ at $4{ }^{\circ} \mathrm{C}$ for $30 \mathrm{~min}$. Then, the precipitate was dissolved in $0.1 \mathrm{M}$ sodium bicarbonate $\left(\mathrm{NaHCO}_{3}\right),(\mathrm{pH} 8.0)$ and then re-acidified and re-centrifuged. Later, chloroform-methanol $(2: 1, \mathrm{v} / \mathrm{v})$ was used to extract the precipitate. The organic phase was evaporated on a rotary evaporator (EYELA NH001S-W, Tokyo Rikakikai, Japan) to remove the solvent. Finally, a viscous dark-brown product was obtained which was the biosurfactant and this was weighed after drying to quantify the yield (El-Sheshtawy et al., 2015).

\section{Solvent extraction}

The supernatant from previous step of centrifugation was treated with a mixture of extraction solvent (methanol/ chloroform/acetone) in the ratio of $1: 1: 1$ by volume. The mixture was transferred to an incubator shaker and continuously shaken at $200 \mathrm{rpm}, 30^{\circ} \mathrm{C}$ for $5 \mathrm{~h}$. At the end of $5 \mathrm{~h}$, two layers of precipitate were obtained. The upper layer was discarded and the bottom layer was left to dry overnight. Finally, the dry powder obtained at the end was weighed on a weighing scale (Mukherjee et al., 2006).

\section{Zinc sulphate precipitation method}

To the supernatant containing biosurfactant, $40 \%$ (w/v) zinc sulphate was gradually added in order to precipitate the biosurfactant. This mixture was kept for incubation at $4{ }^{\circ} \mathrm{C}$ for $24 \mathrm{~h}$. Then, the contents were centrifuged at $8022 \mathrm{~g}, 4^{\circ} \mathrm{C}$ for $30 \mathrm{~min}$ to obtain the biosurfactant, which was then dried by placing the tubes inside a pre-sterilised box lined with filter papers and allowed to stand for 24-48 $\mathrm{h}$ at $27^{\circ} \mathrm{C}$ inside a laminar flow unit until the biosurfactant was dry. Finally, the product was weighed to quantify the yield (Shah et al., 2016).

\section{Antimicrobial activity of biosurfactant}

The antimicrobial activity of the extracted biosurfactant was tested against E. coli ATCC 10536 and S. aureus
ATCC 11632 obtained from UKM culture collection and determined in 96-well plates using a modified microdilution approach (Sambanthamoorthy et al., 2014). Briefly, $100 \mu \mathrm{L}$ of sterile Muller Hinton broth (MHB) was pipetted into the first column of the 96 wells microplate which served as the bacterial control. The second column had $100 \mu \mathrm{L}$ of biosurfactant solution in PBS $(200 \mu \mathrm{g} / \mathrm{mL})$ which was mixed with the medium; this resulted in a biosurfactant concentration of $100 \mu \mathrm{g} / \mathrm{mL}$ and $100 \mu \mathrm{L}$ was transferred serially to two subsequent rows resulting in two-fold dilution of 50 and $25 \mu \mathrm{g} / \mathrm{mL}$, whereas the last column had $10 \mu \mathrm{g} / \mathrm{mL}$ concentration of biosurfactant (prepared separately). Wells without biosurfactant served as negative controls and wells with ampicillin $(50 \mu \mathrm{g} / \mathrm{mL})$ served as positive controls of the assay. All wells were inoculated with $100 \mu \mathrm{L}$ of $10^{8} \mathrm{CFU}$ from a log phase culture of each test strain. The plates were then covered and incubated at $37^{\circ} \mathrm{C}$ for $24 \mathrm{~h}$. All the experiments were done in triplicates. The contents of each well were plated onto LB agar plates with appropriate dilutions and CFU were enumerated the next day. Percent reduction in growth was calculated using the formula below:

$$
\text { Percent reduction }=\frac{\text { Control-Treatment }}{\text { Control }} \times 100
$$

Where, Control= number of CFU for untreated samples; Treatment $=$ number of CFU for samples treated with rhamnolipid biosurfactant

\section{Biosurfactant efficiency}

The extracted biosurfactant which was stored at $-20^{\circ} \mathrm{C}$ in air-tight tubes was used for these experiments. After a period of $1,3,6$ and 9 months, the tubes were picked from the cold storage and left to stand until they reached room temperature. Then, the agar well diffusion assay was performed to learn the effect of storage on the effectiveness of biosurfactant activity (Joshi et al., 2009). Briefly, an overnight nutrient broth culture of test pathogens was prepared, and this was swabbed to make a lawn culture over the Muller-Hinton Agar (MHA) plates using sterile hockey stick. After lawn preparation, the plates were kept aside until the cultures had dried over the agar surface, then using a sterile borer; wells $(8 \mathrm{~mm})$ were punched in agar before loading $100 \mu \mathrm{L}$ biosurfactant solution of $100 \mu \mathrm{g} / \mathrm{mL}$ concentration. Distilled water served as a negative control, whereas ampicillin (50 $\mu \mathrm{g} / \mathrm{mL}$ ) served as the positive control. The plates were incubated for 18-24 $\mathrm{h}$ and results were recorded as the diameter of the zone of inhibition (ZOI).

\section{Statistical analysis}

The data represented for all the experiments is the arithmetic mean of at least three replicates. The variability in mean values has been performed by introduction of standard deviation standard error and variance in the mean values to each experimental output. For the 
comparison of means, T-test was done using IBM SPSS statistics software version 25.

\section{RESULTS AND DISCUSSION}

\section{Biosurfactant detection}

It is highly recommended by Sekhon et al. (2011) to apply more than one detection method to confirm the production of biosurfactant. Therefore, five highly recommended methods were applied. The strain $P$. aeruginosa UKMP14T showed positive results for all the screening methods: drop collapse method, oil spreading assay, emulsification assay, hemolytic assay and CTAB assay.

The biosurfactant solution collapsed in less than a minute on the oil for drop collapse test indicating the presence of biosurfactant in higher levels (Supplementary Figure 1). However, this method is not sensitive enough to detect lower levels of biosurfactant (Youssef et al., 2004). The zone of clearance was observed distinctly, for the oil spreading assay as well, which according to the same researcher is a far more superior assay for testing the presence of biosurfactant. A value of $48.28 \pm 1.67$ was obtained for the $\% \mathrm{El}_{24}$ (Supplementary Figure 2). The value obtained in our study is lower in comparison to the $\% \mathrm{El}_{24}$ values obtained by other researchers (Hamzah et al., 2013; Vijayakumar and Saravanan, 2015; Ferhat et al., 2017). However, the emulsion obtained was highly stable, as it was maintained as it is even after $24 \mathrm{~h}$ of emulsification. Therefore, these results are suggestive of biosurfactant being produced in the culture medium according to previous literature (Willumsen and Karlson 1996).

The results for hemolytic assay correlated well with findings from other researchers (Vijayakumar and Saravanan, 2015). The said researchers found an association between the productions of biosurfactant with that of the hemolytic activity. Pseudomonas aeruginosa UKMP14T showed clear hemolytic zone ( $\beta$-hemolysis; white clearance zone around colony) in the blood agar plates confirming the presence of biosurfactant production (Supplementary Figure 3).

CTAB assay is a semi-quantitative assay for detecting biosurfactant presence, especially the anionic class of biosurfactants such as rhamnolipids (Wu et al., 2008). In our results, a blue color halo was observed surrounding the wells supplemented with supernatant from $P$. aeruginosa culture (Supplementary Figure 4). The principle behind dark blue halo formation is a complexation reaction between the anionic surfactant and cationic methylene blue dye. Similar results were obtained by Vijayakumar and Saravanan (2015) for strain $P$. aeruginosa PB3A used in their study. All the above five detection methods with their respective results are summarized in Table 1.
Table 1: Summary of biosurfactant detection methods

\begin{tabular}{lll}
\hline $\begin{array}{l}\text { Detection } \\
\text { method }\end{array}$ & \multicolumn{1}{c}{ Observation } & \multicolumn{1}{c}{ Inference } \\
\hline $\begin{array}{l}\text { Drop } \\
\text { collapse test }\end{array}$ & $\begin{array}{l}\text { Drop collapsed/ } \\
\text { flattened }\end{array}$ & $\begin{array}{l}\text { Presence of } \\
\text { biosurfactant }\end{array}$ \\
$\begin{array}{l}\text { Oil spreading } \\
\text { assay }\end{array}$ & $\begin{array}{l}\text { zonearance on the surface of } \\
\text { water }\end{array}$ & $\begin{array}{l}\text { Presence of } \\
\text { biosurfactant }\end{array}$ \\
Emulsification & $\begin{array}{l}\text { Formation of emulsion } \\
\text { layer with an } \% E I_{24} \\
\text { value of } 48.28 \pm 1.67\end{array}$ & $\begin{array}{l}\text { Indirect } \\
\text { indication of } \\
\text { biosurfactant } \\
\text { presence }\end{array}$ \\
Haemolytic & $\begin{array}{l}\beta \text {-haemolysis around the } \\
\text { colony }\end{array}$ & $\begin{array}{l}\text { Presence of } \\
\text { biosurfactant }\end{array}$ \\
assay & $\begin{array}{l}\text { Dark blue halo formation } \\
\text { around wells }\end{array}$ & $\begin{array}{l}\text { Presence of } \\
\text { anionic } \\
\text { biosurfactant }\end{array}$ \\
\hline
\end{tabular}

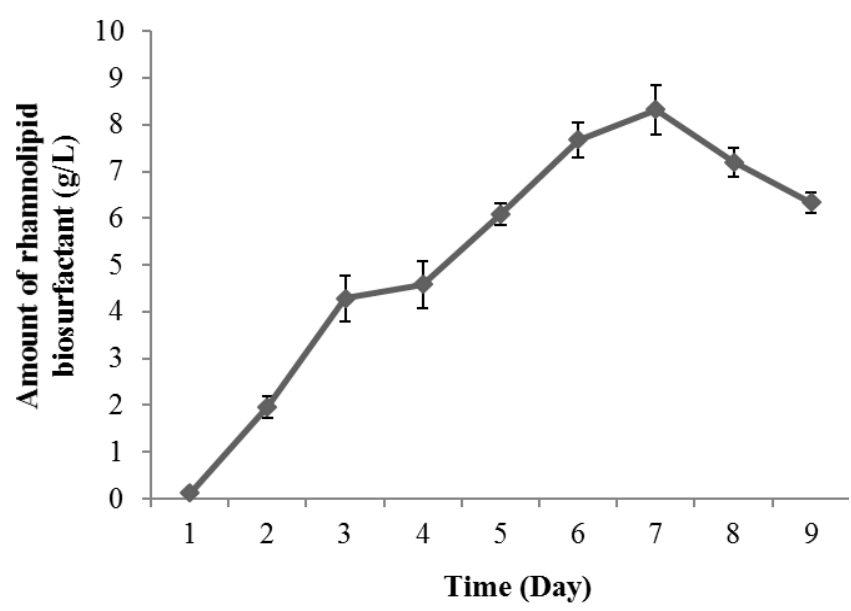

Figure 1: Amount of rhamnolipid biosurfactant produced by $P$. aeruginosa UKMP14T from day 1 to day 9 based on quantification using Anthrone assay.

\section{Optimisation of time interval for biosurfactant production}

The amount of rhamnolipid biosurfactant produced was quantified from the culture medium set up for shake flask experiments after following an incubation period of $1,3,5$, 7 and 9 days using Anthrone method. Rhamnolipid was detected in the culture medium in small quantities within $12 \mathrm{~h}$ of incubation and was found to be about $0.12 \pm 0.04$ $\mathrm{g} / \mathrm{L}$ on day 1 . Then, it was found to increase to $1.96 \pm$ $0.23 \mathrm{~g} / \mathrm{L}$ on day 2 and kept on increasing thereafter. A peak was reached on day 7 and was recorded as the highest value $(8.32 \pm 0.52 \mathrm{~g} / \mathrm{L})$, this was followed by a decrease that was noticed day 8 onwards, falling to 6.33 $\pm 0.20 \mathrm{~g} / \mathrm{L}$ on day 9 (Figure 1). Distinctly, the color of the medium also started to change and appeared to become reddish brown which intensified as the biosurfactant 
production increased in the medium as shown in supplementary figure 5 . Similar results in relation to the appearance of brownish color in the medium have been reported by Patowary et al. (2017).

\section{Biosurfactant recovery}

Various methods have been used till date to recover the biosurfactant from the culture medium (Bodour et al., 2003; Lee et al., 2008; Satpute et al., 2010). Among the three recovery methods that were employed for the biosurfactant extraction in this study, it was found that solvent extraction was superior in comparison to acid precipitation and zinc sulphate precipitation in terms of product yield (Figure 2). Solvent extraction using methanol/chloroform/acetone (1:1:1) gave a white coloured powder having yield of $7.37 \pm 0.81 \mathrm{~g} / \mathrm{L}$ of the culture medium. This can be explained owing to the amphipathic nature of the lipid moiety in the rhamnolipid. The hydrophobic end of this moiety solubilises in the organic solvent and thus can be extracted almost completely. However, this method seemed a bit challenging as compared to zinc sulphate precipitation in terms of separation of the solvent system from the product which resulted in some loss of the product during the procedure. The results from this study were in good agreement with the findings from other researchers both in terms of yield as well as properties (Johny and Saravanakumari, 2013; Sharma et al., 2015).

On the other hand, the second highest value for the amount of biosurfactant recovered was recorded for zinc sulphate precipitation $(5.38 \pm 0.02 \mathrm{~g} / \mathrm{L})$. The biosurfactant was obtained as a white colour powder that was easy to handle and store until further use. A good percent of biosurfactant was extracted using this method as the recovery depends mainly on the ionic charge, and solubility in the desired solvent (Desai and Banat, 1997; Shah et al., 2016).

Furthermore, acid precipitation gave the lowest yield $(2.8 \pm 0.12 \mathrm{~g} / \mathrm{L})$ and also took the longest recovery period of 30 days for complete precipitation of rhamnolipid (Figure 3 ). In addition, the biosurfactant obtained by this method was in the form of a dark brown sticky paste which was difficult to handle and transfer (Supplementary Figure 6). The transfer process of product for storage and further use from the Schott bottle (used for precipitating the rhamnolipid) was a difficult task as the product was in the form of a sticky paste, which led to loss of product. The yield obtained in present study using this method is way higher than the yield obtained by Sabturani et al. (2016) using solvent extraction in combination with acid precipitation (dual recovery method). Table 2 summarises a comparison between these recovery methods and in view of the results obtained in our study. It can be said that zinc sulphate precipitation is a better method in comparison to acid precipitation and organic solvent extraction. This is because long duration is required to recover the rhamnolipid biosurfactant using acid precipitation and two-fold decrease in yield of product compared to what is obtained by zinc sulphate

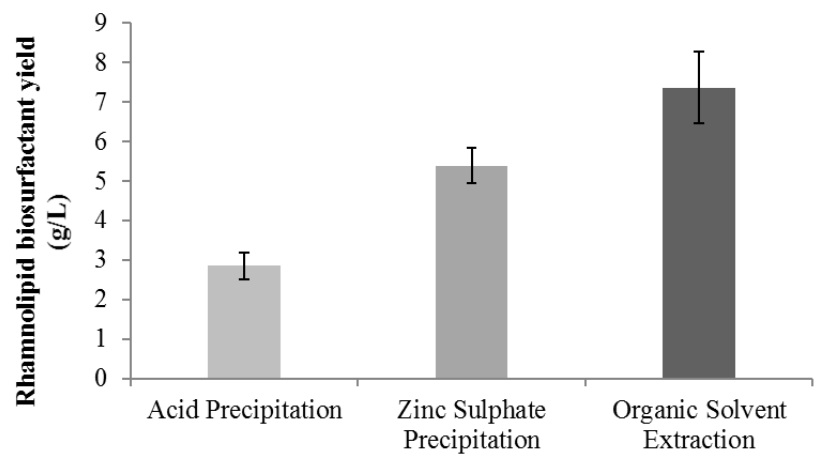

Recovery Methods

Figure 2: A comparison of methods for rhamnolipid biosurfactant recovery following 7 days fermentation.

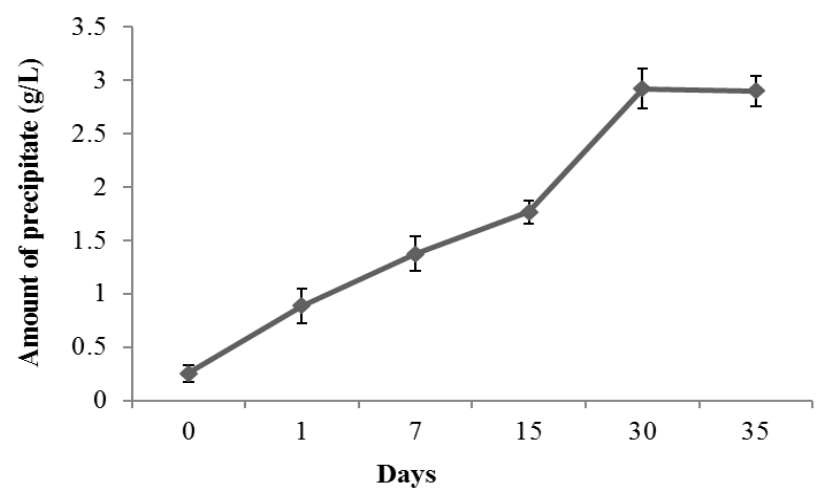

Figure 3: Amount of precipitate of rhamnolipid biosurfactant produced by $P$. aeruginosa UKMP14T using acid precipitation method from day 0 to day 35, measured by weighing dry weight of product.

precipitation. On the other hand, although the yield obtained using organic solvent extraction is higher than that achieved by zinc sulphate precipitation; the problem arises when there was a loss in product yield as explained above. In an industrial set up, it is always prefer the method that consume less time, give higher yields and easy to carry out. Therefore, with all the facts considered, we would prefer zinc sulphate precipitation over the two other methods mentioned herein.

\section{Antimicrobial assay with rhamnolipid biosurfactant}

Biosurfactants have been increasingly suggested for use in a number of industrial sectors such as hydrocarbon emulsification, solubilisation of contaminants in complex hydrocarbons, microbial enhanced oil recovery (MEOR) and so on. Apart from this, biosurfactants have also been proven to be useful as good antimicrobial agents even at lower concentrations which can find applications as biocontrol agents in healthcare sectors. This has been correlated to the incredible surface active properties they possess (Raza et al., 2007). 
Table 2: Comparison of rhamnolipid biosurfactant recovery methods.

\begin{tabular}{|c|c|c|c|c|c|}
\hline 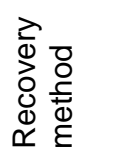 & 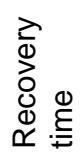 & 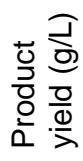 & 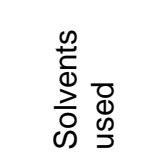 & 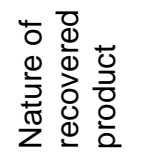 & 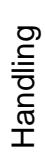 \\
\hline 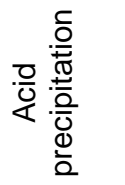 & $\begin{array}{c}30 \\
\text { days }\end{array}$ & $\begin{array}{c}2.8 \\
\pm \\
0.12\end{array}$ & $1 \mathrm{M} \mathrm{HCl}$ & $\begin{array}{l}\text { Blackish- } \\
\text { brown } \\
\text { sticky } \\
\text { paste }\end{array}$ & 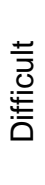 \\
\hline 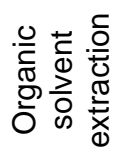 & $24 \mathrm{~h}$ & $\begin{array}{c}7.37 \\
\pm \\
0.81\end{array}$ & $\begin{array}{l}\text { Methanol, } \\
\text { chloroform, } \\
\text { acetone } \\
\quad(1: 1: 1)\end{array}$ & $\begin{array}{l}\text { White } \\
\text { coloured } \\
\text { powder }\end{array}$ & 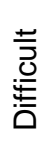 \\
\hline 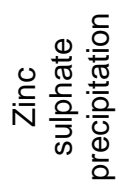 & $24 \mathrm{~h}$ & $\begin{array}{c}5.38 \\
\pm \\
0.02\end{array}$ & $\begin{array}{c}\text { Zinc } \\
\text { sulphate }\end{array}$ & $\begin{array}{l}\text { Light } \\
\text { brown } \\
\text { colour } \\
\text { powder }\end{array}$ & क्षे \\
\hline
\end{tabular}

The antimicrobial activities of biosurfactant are shown by many researchers using various environmental and clinical isolates for testing. Vijaykumar and Saravanan (2015) have shown significant antimicrobial activity of biosurfactant produced from $P$. aeruginosa strain PB3A against pathogens $S$. aureus, Staphylococcus epidermidis, E. coli and $P$. aeruginosa. The antimicrobial activity of lipopeptide surfactants produced from $B$. subtilis was successfully demonstrated by Tsuge et al. (1996). Another researcher, Kiran et al. (2010) showed similar results using a biosurfactant produced from Candida antartica.

Therefore, in our study, the extracted rhamnolipid biosurfactant was tested against two E. coli ATCC 10536 and S. aureus ATCC 11632 in order to study its antimicrobial potential. Interestingly, it was found to be effective on both the test bacteria starting from as low as $10 \mu \mathrm{g} / \mathrm{mL}$ concentration in comparison to results obtained by Sambanthamoorthy et al. (2014). The said researcher used biosurfactant produced from Lactobacillus jensenii and $L$. rhamnosus. In the mentioned study, biosurfactant concentration of $50 \mathrm{mg} / \mathrm{mL}$ was found to be effective on the test bacteria; $E$. coli, and methicillin-resistant $S$. aureus (MRSA), which is very high compared to the concentrations we have used in our study (highest being $100 \mu \mathrm{g} / \mathrm{mL}$ ). Activity accounting to $100 \%$ was obtained in their study with the biosurfactant from $L$. jensenii and between $72-85 \%$ for biosurfactant from $L$. rahmnosus against $E$. coli and $80 \%$ and $93 \%$ for $S$. aureus UAMS-1 and MRSA, respectively. However, in our study, highest antibacterial activity of $95.05 \%$ and $91.89 \%$ cell death was recorded for E. coli ATCC 10536 and S. aureus ATCC
Table 3: Antimicrobial activity of rhamnolipid biosurfactant extracted using acid precipitation and measured using modified microdilution method.

\begin{tabular}{ccc}
\hline \multirow{2}{*}{$\begin{array}{c}\text { Concentration } \\
\text { of rhamnolipid } \\
(\mu \mathrm{g} / \mathrm{mL})\end{array}$} & \begin{tabular}{c} 
E. coli ATCC \\
\cline { 2 - 3 }
\end{tabular} & $\begin{array}{c}\text { S. aureus ATCC } \\
10536\end{array}$ \\
\hline 10 & $37.30 \pm 7.63$ & $29.10 \pm 8.18$ \\
25 & $51.80 \pm 10.26$ & $49.46 \pm 5.29$ \\
50 & $76.64 \pm 7.23$ & $70.22 \pm 0.57$ \\
100 & $95.05 \pm 1.15$ & $91.89 \pm 1.52$ \\
$\begin{array}{c}\text { Ampicillin } \\
(50 \mu \mathrm{g} / \mathrm{mL})^{*}\end{array}$ & $96.45 \pm 1.52$ & $95.29 \pm 2.08$ \\
$\begin{array}{l}{ }^{*} \text { Ampicillin }(50 \mu \mathrm{g} / \mathrm{mL}) \\
\text { experiment. }\end{array}$ &
\end{tabular}

Table 4: Zone of inhibition produced by rhamnolipid biosurfactants at different intervals of storage period at $20{ }^{\circ} \mathrm{C}$.

\begin{tabular}{lcccc}
\hline & \multicolumn{4}{c}{ Zone of inhibition (mm) } \\
\cline { 2 - 5 } Test & \multicolumn{4}{c}{ Storage period } \\
organism & $\begin{array}{c}\text { Positive } \\
\text { control }\end{array}$ & $\begin{array}{c}1 \\
\text { month }\end{array}$ & $\begin{array}{c}\text { months } \\
\text { months }\end{array}$ \\
\hline E. coli & $18.7 \pm$ & $12.33 \pm$ & $12.5 \pm$ & $11.8 \pm$ \\
ATCC & 1.21 & 0.58 & 0.28 & 0.41 \\
10536 & 1.28 & & & \\
S. aureus & $10.7 \pm$ & $7.9 \pm$ & $8.2 \pm$ & $8.0 \pm$ \\
ATCC & 1.63 & 0.80 & 0.77 & 0.26 \\
11632 & & & & \\
\hline
\end{tabular}

Rhamnolipid biosurfactant $(100 \mu \mathrm{g} / \mathrm{mL})$ was used for testing. Cephalosporin $(50 \mu \mathrm{g} / \mathrm{mL})$ was used as positive control against $E$. coli ATCC 10536 and Tetracycline $(50 \mu \mathrm{g} / \mathrm{mL})$ was used as positive control against $S$. aureus ATCC 11632.

11632, respectively at $100 \mu \mathrm{g} / \mathrm{mL}$ concentration of rhamnolipid biosurfactant. The values represented are the percent reduction in cell numbers when treated with rhamnolipid biosurfactant. Percentage reduction in growth has been presented in Table 3 and the results are from three independent preparations of rhamnolipid biosurfactant.

\section{Effect of aging on rhamnolipid biosurfactant efficiency}

Diameter of zone of inhibition (ZOI) recorded at different time intervals (1, 3 and 6 months) showed no significant difference in values. This shows that the rhamnolipid biosurfactant is good to use even up to a storage period of 6 months when stored at $-20{ }^{\circ} \mathrm{C}$. The results of this assay are provided in Table 4. 


\section{CONCLUSION}

The ability of $P$. aeruginosa UKMP14T to produce rhamnolipid biosurfactant was successfully detected. The biosurfactant production period was optimised, so that the future scale-up becomes easy and practically applicable even for large scale production. Although rhamnolipid biosurfactant possess unique properties making them advantageous over the synthetic surfactants, their usage is not fully flourished. This is due to the enormous financial input and industrially infeasible techniques demanded for the recovery of final product. Therefore, through our comparative analysis, we have pointed out a better method among the three common methods employed for rhamnolipid biosurfactant recovery. Although organic solvent extraction gave the highest yield, product recovery using zinc sulphate precipitation was much easier and feasible method in terms of recovery technique used and time consumption. In addition, the rhamnolipid biosurfactant recovered by zinc sulphate precipitation was easy to store for further usage. Lastly, rhamnolipid biosurfactant showed antimicrobial activity against clinically important bacteria like E. coli ATCC 10536 and S. aureus ATCC 11632. The findings from this research are surely a key factor in promoting rhamnolipid biosurfactant application in diverse fields, especially in combating the clinically prominent bacteria like E. coli and S. aureus.

\section{ACKNOWLEDGEMENTS}

We thank Universiti Kebangsaan Malaysia for funding this research under the Research University Grants (GUP2018-112). We also extend our thanks to Directorate of Minorities, Karnataka, Government of India for providing fellowship to the student.

\section{REFERENCES}

Bailey, R. W. (1958). The reaction of pentoses with anthrone. Biochemical Journal 68(4), 669-672.

Banat, I. M., Franzetti, A., Gandolfi, I., Bestetti, G., Martinotti, M. G., Fracchia, L. and Marchant, R. (2010). Microbial biosurfactants production, applications and future potential. Applied Microbiology and Biotechnology 87(2), 427-444.

Banat, I. M., Makkar, R. S. and Cameotra, S. S. (2000). Potential commercial applications of microbial surfactants. Applied Microbiology and Biotechnology 53(5), 495-508.

Bodour, A. A., Drees, K. P. and Maier, R. M. (2003). Distribution of biosurfactant-producing bacteria in undisturbed and contaminated arid southwestern soils. Applied and Environmental Microbiology 69(6), 3280-3287.

Bodour, A. A. and Miller-Maier, R. M. (1998). Application of a modified drop-collapse technique for surfactant quantitation and screening of biosurfactant-producing microorganisms. Journal of Microbiological Methods 32(3), 273-280.
Carrillo, P. G., Mardaraz, C., Pitta-Alvarez, S. I. and Giulietti, A. M. (1996). Isolation and selection of biosurfactant-producing bacteria. World Journal of Microbiology and Biotechnology 12(1), 82-84.

Cooper, D. G. and Goldenberg, B. G. (1987). Surfaceactive agents from two Bacillus species. Applied and Environmental Microbiology 53(2), 224-229.

Desai, J. D. and Banat, I. M. (1997). Microbial production of surfactants and their commercial potential. Microbiology and Molecular Biology Reviews 61(1), 47-64.

El-Amine Bendaha, M., Mebrek, S., Naimi, M., Tifrit, A. and Belaouni, H. A. (2012). Isolation and comparison of rhamnolipids production in Pseudomonas aeruginosa PB: 2 and Pseudomonas fluorescens PV: 10. Scientific Reports 1(12), 544.

El-Sheshtawy, H. S., Aiad, I., Osman, M. E., AboELnasr, A. A. and Kobisy, A. S. (2015). Production of biosurfactant from Bacillus licheniformis for microbial enhanced oil recovery and inhibition the growth of sulfate reducing bacteria. Egyptian Journal of Petroleum 24(2), 155-162.

Ferhat, S., Alouaoui, R., Badis, A. and Mostefa, N. M. (2017). Production and characterization of biosurfactant by free and immobilized cells from Ochrobactrum intermedium isolated from the soil of southern Algeria with a view to environmental application. Biotechnology and Biotechnological Equipment 31(4), 733-742.

Fracchia, L., Cavallo, M., Martinotti, M. G. and Banat, I. M. (2012). Biosurfactants and bioemulsifiers biomedical and related applications - present status and future potentials. Biomedical Science, Engineering and Technology 14, 326-335.

Gudina, E. J., Rangarajan, V., Sen, R. and Rodrigues, L. R. (2013). Potential therapeutic applications of biosurfactants. Trends in Pharmacological Sciences 34(12), 667-675.

Hamzah, A., Rabu, A., Azmy, R. F. H. R. and Yussoff, N. A. (2010). Isolation and characterization of bacteria degrading Sumandak and South Angsi oils. Sains Malaysiana 39(2), 161-168.

Hamzah, A., Sabturani, N. and Radiman, S. (2013). Screening and optimization of biosurfactant production by the hydrocarbon-degrading bacteria. Sains Malaysiana 42(5), 615-623.

Irie, Y., O'toole, G. A. and Yuk, M. H. (2005). Pseudomonas aeruginosa rhamnolipids disperse Bordetella bronchiseptica biofilms. FEMS Microbiology Letters 250(2), 237-243.

Johny, J. M. and Saravanakumari, P. (2013). Comparative study: Different recovery techniques of biosurfactant produced from Pichia fermentans isolated from fermented dairy whey waste. World Journal of Pharmacy and Pharmaceutical Sciences 3(1), 567-582.

Joshi, B., Lekhak, S. and Sharma, A. (2009). Antibacterial property of different medicinal plants: Ocimum sanctum, Cinnamomum zeylanicum, Xanthoxylum armatum and Origanum majorana. 
Kathmandu University Journal of Science, Engineering and Technology 5(1), 143-150.

Kiran, G. S., Thomas, T. A., Selvin, J., Sabarathnam, B. and Lipton, A. P. (2010). Optimization and characterization of a new lipopeptide biosurfactant produced by marine Brevibacterium aureum MSA13 in solid state culture. Bioresource Technology 101, 2389-2396.

Lee, S. C., Lee, S. J., Kim, S. H., Park, I. H., Lee, Y. S., Chung, S. Y. and Choi, Y. L. (2008). Characterization of new biosurfactant produced by Klebsiella sp. Y6-1 isolated from waste soybean oil. Bioresource Technology 99(7), 2288-2292.

Magalhaes, L. and Nitschke, M. (2013). Antimicrobial activity of rhamnolipids against Listeria monocytogenes and their synergistic interaction with nisin. Food Control 29(1), 138-142.

Mukherjee, S., Das, P. and Sen, R. (2006). Towards commercial production of microbial surfactants. Trends in Biotechnology 24(11), 509-515.

Muthusamy, K., Gopalakrishnan, S., Ravi, T. K. and Sivachidambaram, P. (2008). Biosurfactants: Properties, commercial production and application. Current Science 94(6), 736-747.

Nalini, S. and Parthasarathi, R. (2014). Production and characterization of rhamnolipids produced by Serratia rubidaea SNAU02 under solid-state fermentation and its application as biocontrol agent. Bioresource Technology 173, 231-238.

Nitschke, M. and Costa, S. G. V. A. O. (2007). Biosurfactants in food industry. Trends in Food Science \& Technology 18(5), 252-259.

Patowary, K., Patowary, R., Kalita, M. C. and Deka, S. (2017). Characterization of biosurfactant produced during degradation of hydrocarbons using crude oil as sole source of carbon. Frontiers in Microbiology $\mathbf{8}$, 279.

Raza, Z. A., Rehman, A., Khan, M. S. and Khalid, Z. M. (2007). Improved production of biosurfactant by a Pseudomonas aeruginosa mutant using vegetable oil refinery wastes. Biodegradation 18(1), 115-121.

Rikalovic, M., Gojgic-Cvijovic, G, Vrvic, M. and Karadzic, I. (2012). Production and characterization of rhamnolipids from Pseudomonas aeruginosa san ai. Journal of the Serbian Chemical Society 77(1), 27-42.

Rodrigues, L., Van der Mei, H. C., Teixeira, J. and Oliveira, R. (2004). Influence of biosurfactants from probiotic bacteria on formation of biofilms on voice prostheses. Applied and Environmental Microbiology 70(7), 4408-4410.

Sabturani, N., Latif, J., Radiman, S. and Hamzah, A. (2016). Spectroscopic analysis of rhamnolipid produced by Pseudomonas aeruginosa UKMP14T. Malaysian Journal of Analytical Sciences 20(1), 31-43.

Satpute, S. K., Banpurkar, A. G., Dhakephalkar, P. K., Banat, I. M. and Chopade, B. A. (2010). Methods for investigating biosurfactants and bioemulsifiers: A review. Critical Reviews in Biotechnology 30(2), 127144.
Sambanthamoorthy, K., Feng, X., Patel, R., Patel, S. and Paranavitana, C. (2014). Antimicrobial and antibiofilm potential of biosurfactants isolated from lactobacilli against multi-drug-resistant pathogens. BMC Microbiology 14(1), 197.

Sekhon, K. K., Khanna, S. and Cameotra, S. S. (2011). Enhanced biosurfactant production through cloning of three genes and role of esterase in biosurfactant release. Microbial Cell Factories 10(1), 49.

Shah, M. U. H., Sivapragasam, M., Moniruzzaman, M. and Yusup, S. B. (2016). A comparison of recovery methods of rhamnolipids produced by Pseudomonas aeruginosa. Procedia Engineering 148, 494-500.

Sharma, D., Ansari, M. J., Al-Ghamdi, A., Adgaba, N., Khan, K. A., Pruthi, V. and Al-Waili, N. (2015). Biosurfactant production by Pseudomonas aeruginosa DSVP20 isolated from petroleum hydrocarboncontaminated soil and its physicochemical characterization. Environmental Science and Pollution Research 22(22), 17636-17643.

Shekhar, S., Sundaramanickam, A. and Balasubramanian, T. (2015). Biosurfactant producing microbes and their potential applications: A review. Critical Reviews in Environmental Science and Technology 45(14), 1522-1554.

Soberon-Chavez, G. and Maier, R. M. (2011). Biosurfactants: A general overview. In: Biosurfactants. Soberón-Chávez, G. (ed.). Springer, Berlin, Heidelberg. pp. 1-11.

Tsuge, K., Ano, T. and Shoda, M. (1996). Isolation of a gene essential for biosynthesis of the lipopeptide antibiotices plipastatin B1 and surfactin in Bacillus subtilis YB8. Archives of Microbiology 165, 243-251.

Vatsa, P., Sanchez, L., Clement, C., Baillieul, F. and Dorey, S. (2010). Rhamnolipid biosurfactants as new players in animal and plant defense against microbes. International Journal of Molecular Sciences 11(12), 5095-5108.

Vijayakumar, S. and Saravanan, V. (2015). In vitro cytotoxicity and antimicrobial activity of biosurfactant produced by Pseudomonas aeruginosa strain PB3A. Asian Journal of Scientific Research 8(4), 510.

Willumsen, P. A. and Karlson, U. (1996). Screening of bacteria, isolated from $\mathrm{PAH}$-contaminated soils, for production of biosurfactants and bioemulsifiers. Biodegradation 7(5), 415-423.

Wu, J. Y., Yeh, K. L., Lu, W. B., Lin, C. L. and Chang, J. S. (2008). Rhamnolipid production with indigenous Pseudomonas aeruginosa EM1 isolated from oilcontaminated site. Bioresource Technology 99(5), 1157-1164.

Youssef, N. H., Duncan, K. E., Nagle, D. P., Savage, K. N., Knapp, R. M. and Mclnerney, M. J. (2004). Comparison of methods to detect biosurfactant production by diverse microorganisms. Journal of Microbiological Methods 56(3), 339-347. 
Malays. J. Microbiol. Vol 17(2) 2021, pp. 103-112

DOI: http://dx.doi.org/10.21161/mjm.200758

\section{SUPPLEMENTARY INFORMATION}

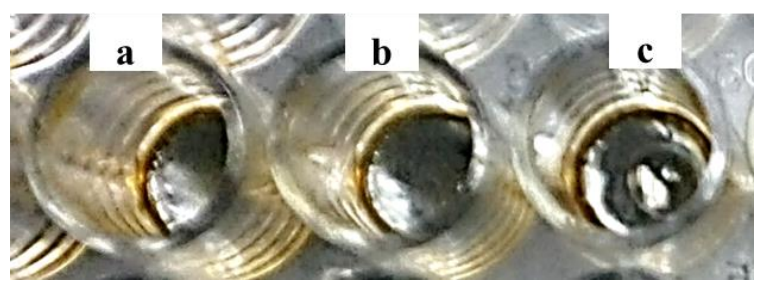

Supplementary Figure 1: Drop collapse assay with a) supernatant from $P$. aeruginosa UKMP14T culture (test), b) $1 \%$ SDS (positive control) and c) distilled water (negative control). Drop has collapsed in well (a) and (b), whereas remained beaded in (c).

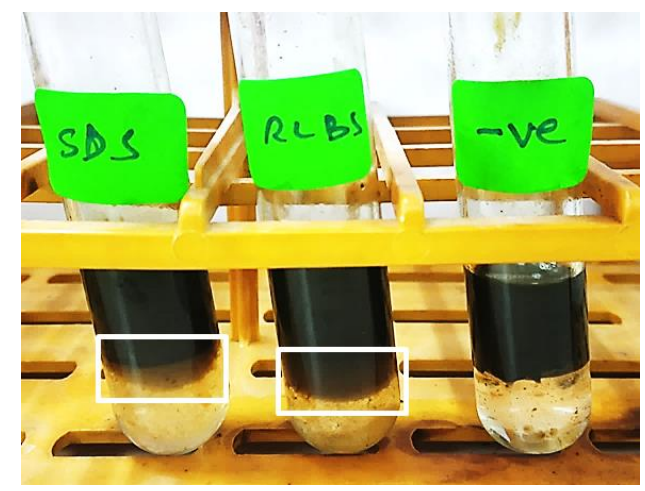

Supplementary Figure 2: Emulsion layer formed upon mixing of crude oil with (a) SDS-positive control, (b) supernatant from $P$. aeruginosa UKMP14T - test and (c) sterile distilled water - negative control. Emulsification layer has been highlighted in the figure using a white box.

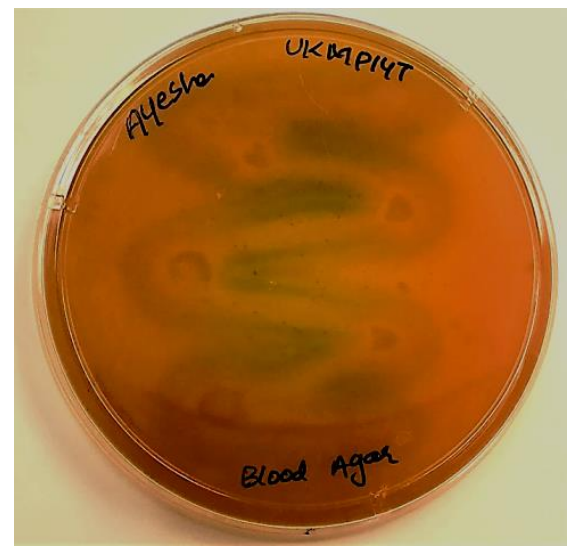

Supplementary Figure 3: Beta-hemolysis on blood agar produced by culture supernatant of $P$. aeruginosa UKMP14T.

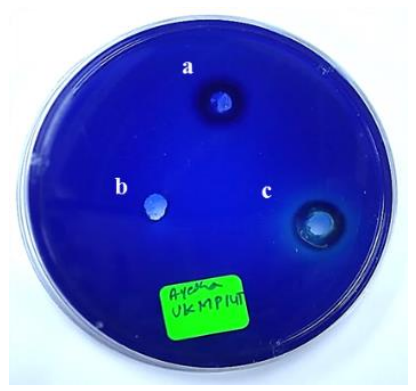

Supplementary Figure 4: Methylene Blue agar plate with (a) SDS (positive control), (b) sterile distilled water (negative control) and (c) supernatant from $P$. aeruginosa UKMP14T. Dark blue halo around the wells is indication of anionic surfactant presence.

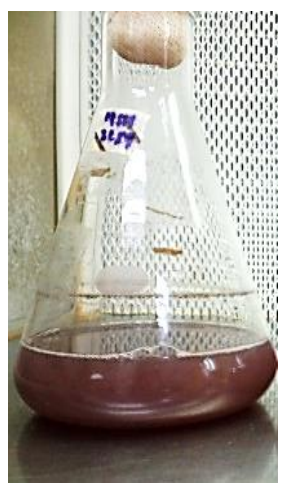

Supplementary Figure 5: Flasks containing $P$. aeruginosa UKMP14T on day 7 showing reddish-brown colour due to production of rhamnolipid biosurfactant.

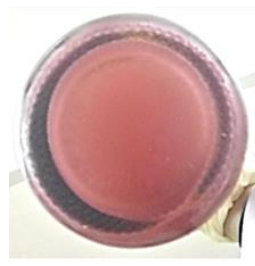

(a)

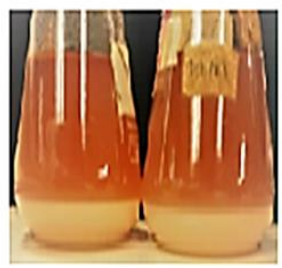

(b)

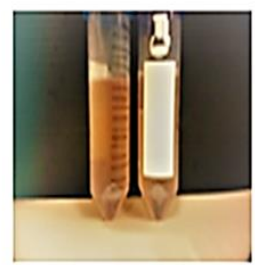

(c)
Supplementary Figure 6: Recovery of rhamnolipid biosurfactant from $P$. aeruginosa UKMP14T using three approaches (a) Blackish- brown precipitate obtained at the bottom of a Schott bottle on $30^{\text {th }}$ day of precipitation using acid precipitation (b) White colour precipitate obtained on organic solvent extraction and (c) Light brown colour precipitate obtained by zinc sulphate precipitation. 